\title{
Uniform and stable plasma reactivity: Effects of nanosecond pulses and oxygen addition in atmospheric-pressure dielectric barrier discharges
}

Cite as: J. Appl. Phys. 129, 033302 (2021); https://doi.org/10.1063/5.0031220

Submitted: 28 September 2020 . Accepted: 29 December 2020 . Published Online: 15 January 2021

(D) Feng Liu, (D) Haijing Chu, Yue Zhuang, (D) Zhi Fang, Renwu Zhou, Patrick J. Cullen, and Kostya (Ken) Ostrikov

\section{COLLECTIONS}

Paper published as part of the special topic on Fundamentals and Applications of Atmospheric Pressure Plasmas ATMPP2021
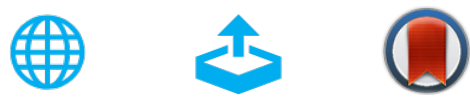

\section{ARTICLES YOU MAY BE INTERESTED IN}

Theoretical and experimental study of a monocharged electret for pressure sensor applications

Journal of Applied Physics 129, 034501 (2021); https://doi.org/10.1063/5.0030671

The role of a dielectric barrier in single-filament discharge over a water surface Journal of Applied Physics 129, 043301 (2021); https://doi.org/10.1063/5.0035186

In situ millimeter wave spectroscopy of microplasma within a photonic crystal Journal of Applied Physics 129, 033301 (2021); https://doi.org/10.1063/5.0032522

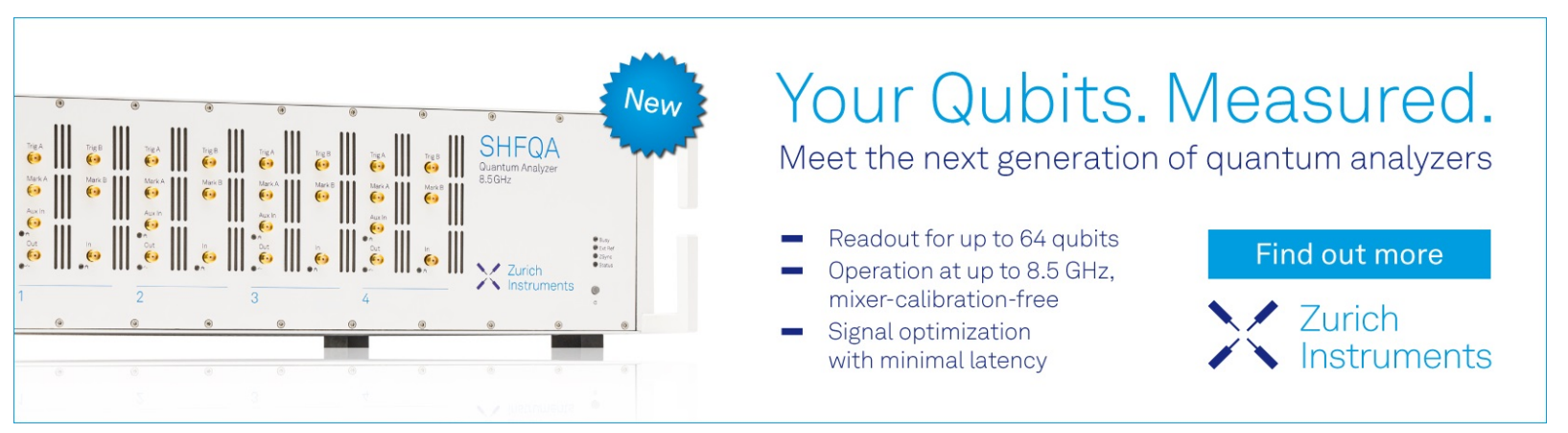




\title{
Uniform and stable plasma reactivity: Effects of nanosecond pulses and oxygen addition in atmospheric-pressure dielectric barrier discharges
}

\author{
Cite as: J. Appl. Phys. 129, 033302 (2021); doi: 10.1063/5.0031220 \\ Submitted: 28 September 2020 - Accepted: 29 December 2020 . \\ Published Online: 15 January 2021
}

Feng Liu, ${ }^{7}$ (D) Haijing Chu, ${ }^{7}$ (D) Yue Zhuang, ${ }^{7}$ Zhi Fang, $^{1, a)}$ (D) Renwu Zhou, ${ }^{2}$ Patrick J. Cullen, ${ }^{2}$ and Kostya (Ken) Ostrikov ${ }^{3,4}$

\author{
AFFILIATIONS \\ ${ }^{1}$ College of Electrical Engineering and Control Science, Nanjing Tech University, Nanjing 211816, China \\ ${ }^{2}$ School of Chemical and Biomolecular Engineering, The University of Sydney, Sydney, NSW 2006, Australia \\ ${ }^{3}$ School of Chemistry and Physics, Queensland University of Technology, Brisbane, QLD 4000, Australia \\ ${ }^{4}$ Joint CSIRO-QUT Sustainable Processes and Devices Laboratory, P.O. Box 218, Lindfield, NSW 2070, Australia
}

Note: This paper is part of the Special Topic on Fundamentals and Applications of Atmospheric Pressure Plasmas.

${ }^{a}$ Author to whom correspondence should be addressed: myfz@263.net

\begin{abstract}
Uniform and stable reactivity of atmospheric pressure plasmas is a prerequisite for most applications in fields ranging from materials' surface processing, environment protection, to energy conversion. Dielectric barrier discharges (DBDs) are among the most promising plasmas to satisfy these requirements. However, the unpredictable and uncontrollable transitions between discharge modes, the limited understanding of the DBD ignition and extinction processes, and the complexity of plasma chemistries and reactions with admixture gases restrict their adoption in industry. Here, we report a practically relevant and elegant solution based on using customized nanosecond (ns) pulse excitation and precise addition of oxygen to an Ar flow. The effects of ns pulses and oxygen on the uniformity and reactivity of the DBD are investigated via quantifying the gap voltage $U_{\mathrm{g}}$ and the discharge current $I_{\mathrm{g}}$ from the current-voltage measurements and quantitative discharge imaging. The electron density, $n_{\mathrm{e}}$, is estimated with $U_{\mathrm{g}}$ and $I_{\mathrm{g}}$. With increasing $U_{\mathrm{g}}$, more electron avalanches are ignited and overlap, which facilitate $n_{\mathrm{e}}, T_{\mathrm{e}}$, and discharge uniformity, while high $U_{\mathrm{g}}$ induces excessive electrons generated with high ionization rates, resulting in the distortion of the space electric field and reduced stability and uniformity. A small amount of added oxygen favors the production of electrons. Overdosed oxygen molecules capture electrons causing a drop in $n_{\mathrm{e}}$ and $T_{\mathrm{e}}$ and couple with the effect of the electrical field resulting in the filamentary discharges or complete plasma extinction. The mechanism of the effects of ns pulses and oxygen addition on the uniformity and reactivity of plasmas is based on the electrical measurements and discharge image analysis and is crossvalidated by optical emission spectra measurements and the ratio of the Ar intensities' calculations as indicators of the variation in $n_{\mathrm{e}}$ and $T_{\mathrm{e}}$. The results in this work contribute to the realization and controllability of uniform, stable, and reactive plasmas at atmospheric pressure.
\end{abstract}

Published under license by AIP Publishing. https://doi.org/10.1063/5.0031220

\section{INTRODUCTION}

Low pressure plasma processes can be precisely controlled and have desirable spatial uniformity and temporal stability, which are crucial for many applications, including atomic layer deposition and etching ${ }^{1,2}$ and micro-nano-pattern surface functional modifications. ${ }^{3,4}$ With the advantages of short processing time, low energy consumption, and without the need for vacuum equipment, atmospheric pressure plasmas have recently been actively investigated and achieved inspiring results in materials processing, ${ }^{5,6}$ environment protection, ${ }^{7,8}$ energy conversion and storage, ${ }^{9-11}$ and other areas. However, from the industrial application point of view, it is necessary to achieve uniform plasmas with stable reactivity. At atmospheric pressure, the electron mean-free path is small (less than $1 \mathrm{~mm}$ ), and in order to obtain sufficient ionization and discharge ignition energy, the applied electrical field between the electrodes needs to be high, which enhances the difficulty to maintain 
the plasma uniformity and stability especially during industrial processes. Due to the dielectric layer(s) between the electrodes limiting the current and preventing arc formation, dielectric barrier discharges (DBDs) are among the most promising methods to provide uniform and stable plasmas. ${ }^{12,13}$

Due to their short discharge duration and high breakdown voltage, pulsed voltage excited discharges are among the main choices to improve the plasma uniformity and reactivity. ${ }^{14-18}$ Nevertheless, in pulsed DBDs, because of the unclear understanding of the ignition and extinction processes, especially with reactive admixtures, the uniformity and stability are still uncontrollable. The two key problems are due to insufficient design of pulses to monitor the excitation electric field and the instability caused by the added reactive gases. Without a comprehensive understanding and solving of these problems, the discharge evolution in fasttimescales is unpredictable, which results in poor discharge stability and cannot meet the requirements for industrial processing. ${ }^{19,20}$

For specific applications requiring unique plasma chemistry, reactive admixtures need to be added to the DBD which participate in the physicochemical processes and greatly enhance the chemical reactivity. ${ }^{21-24}$ The plasma chemistry is determined by the plasma chemical reaction rates, largely initiated by energetic electrons, which depend on the electron energy distribution function (EEDF). For pulsed DBDs, the breakdown voltage is high and the plasma excitation electric field changes dramatically during the breakdown. With the added reactive species, the plasma chemistry and the space charges distort the EEDF, initially shaped by the applied electric field, as well as the discharge uniformity and stability. Therefore, it is extremely challenging to control and monitor the plasma uniformity and reactivity with reactive admixtures. ${ }^{22,25-27}$

Oxygen addition can produce a diverse range of reactive oxygen species that are used in film etching, volatile organic compounds (VOCs) oxidation, and biomedical treatments. ${ }^{28-30} \mathrm{~A}$ small amount of oxygen can promote Penning ionization and electron avalanches with inert gas discharges, and with the excessive oxygen added, the number of electron is reduced by forming $\mathrm{O}_{2}^{-}$ions, which aggravate the uneven distribution of the electric field and easily form filaments in a discharge gap. ${ }^{20,31-33}$ For pulsed DBDs, in particular, due to the presence of a dielectric barrier, the plasma excitation electric field does not depend on the applied voltage but rather the voltage drop across the discharge gap, which cannot be measured directly. ${ }^{17,34}$ Owing to the difficulty of monitoring the voltage across the discharge gap and the sensitivity of reactive species on plasma chemistry, the uniformity, stability, and reactivity of pulsed DBDs are difficult to control by simply adjusting the process parameters. For the purpose of optimizing the plasma reactivity and uniformity of the oxygen containing pulsed DBD in applications, it is important to understand the discharge phenomena, which determine the behavior of the discharge.

In this work, a practical approach is proposed to investigate the effects of nanosecond (ns) pulses and precisely dosed oxygen on the pulsed DBD plasma uniformity and reactivity. The voltage on the discharge gap and discharge current are estimated from the measured applied voltage and current to explore the effects of the electric field and space charges on discharge uniformity quantified by time-integrated discharge imaging and analysis. Optical emission spectroscopy measurements are used as an indicator of plasma reactivity, and the variation of $T_{\mathrm{e}}$, and cross-validate the results obtained from the study of electrical characteristics. With the tuning of the applied electric field and space charges, the discharge uniformity and reactivity are optimized. The findings and mechanism in this work will help improve atmospheric pressure plasma uniformity and reactivity, ultimately advancing practical applications.

\section{EXPERIMENTAL SETUP}

The experimental setup is illustrated schematically in Fig. 1. It is composed of an ns pulse power supply, an electrical measurement system, an optical measurement system, a discharge reactor, and a gas supply system. The voltage of the ns pulse power supply (Xi'an Lingfeng source HV-2015) can be continuously adjusted from 0 to $15 \mathrm{kV}$ at a pulse repetition frequency (PRF) from 0 to $100 \mathrm{kHz}$. The rising $\left(t_{\mathrm{r}}\right)$ and falling $\left(t_{\mathrm{f}}\right)$ times of the voltage are in the range of $50-500 \mathrm{~ns}$, and the pulse width $\left(t_{\mathrm{w}}\right)$ time is in the range of $0-1 \mathrm{~ms}$. During the experiment, the PRF is fixed at $5 \mathrm{kHz}$, both $t_{\mathrm{r}}$ and $t_{\mathrm{f}}$ are fixed at $50 \mathrm{~ns}$ and $t_{\mathrm{w}}$ is fixed at $1200 \mathrm{~ns}$. The reactor is made of stainless-steel and can be pumped down to the vacuum below $2 \mathrm{~Pa}$. The stainless-steel parallel plate electrode ( $50 \mathrm{~mm}$ in diameter and $5 \mathrm{~mm}$ in thickness) is placed in the center of the reactor with a quartz glass $(80 \mathrm{~mm}$ in diameter and $2 \mathrm{~mm}$ in thickness) covering the ground plate. The gas gap can be adjusted from 0 to $40 \mathrm{~mm}$ and is fixed at $2 \mathrm{~mm}$ during the experiment.

The voltage and current are measured with a 1:1000 highvoltage probe (North Star Research Inc., PVM-5), a current probe (Pearson 6560), and an oscilloscope (Tektronix TDS 3052B). A reference capacitor $\left(C_{\mathrm{r}}\right)$ of $2.2 \mathrm{nF}$ is inserted in series with the ground electrode. The voltage across $C_{\mathrm{r}}$ is measured using a 1:10 voltage probe (Tektronix P6139) to estimate the voltage on the dielectric barrier. The optical emission spectra emitted from the discharge are measured by a spectrometer (Ocean Optic HR4000CG, 250-900 nm range, $0.7 \mathrm{~nm}$ resolution) with $100 \mathrm{~ms}$ integrated time for 500 discharges. The discharge images are recorded by a digital camera (Canon EOS 6D) with $1 / 8 \mathrm{~s}$ exposure time. High purity $\mathrm{Ar}(99.999 \%)$ and $\mathrm{O}_{2}$ (99.999\%) and a mixture gas of $1 \% \mathrm{O}_{2}$ in Ar are used as discharge gases and are controlled by mass flow meters (Sevenstar D08-4F). The studied $\mathrm{O}_{2}$ content ranges from $0.01 \%$ to $10 \%$. The background impurities have no significant influence on the experimental results.

\section{RESULTS AND DISCUSSIONS}

\section{A. Discharge uniformity of argon DBD}

The uniformity of discharge is closely related with the plasma treatment effect, which is mainly determined by the space electric field in our studied system. The adjustment of the applied voltage can effectively influence the electric field in the gas gap in a DBD and the discharge uniformity. Figure 2 shows the discharge images of the Ar DBD at different applied voltages from $3.1 \mathrm{kV}$ to $5 \mathrm{kV}$. The exposure time of the digital camera with $1 / 8 \mathrm{~s}$ is the integration result of 625 times discharge. The uniformity of discharge in this study is not a time-resolved result but an integrated effect, which is useful for plasma treatment in industrial applications. It can be observed that at $3.1 \mathrm{kV}$, the discharge is weak while the plasma 


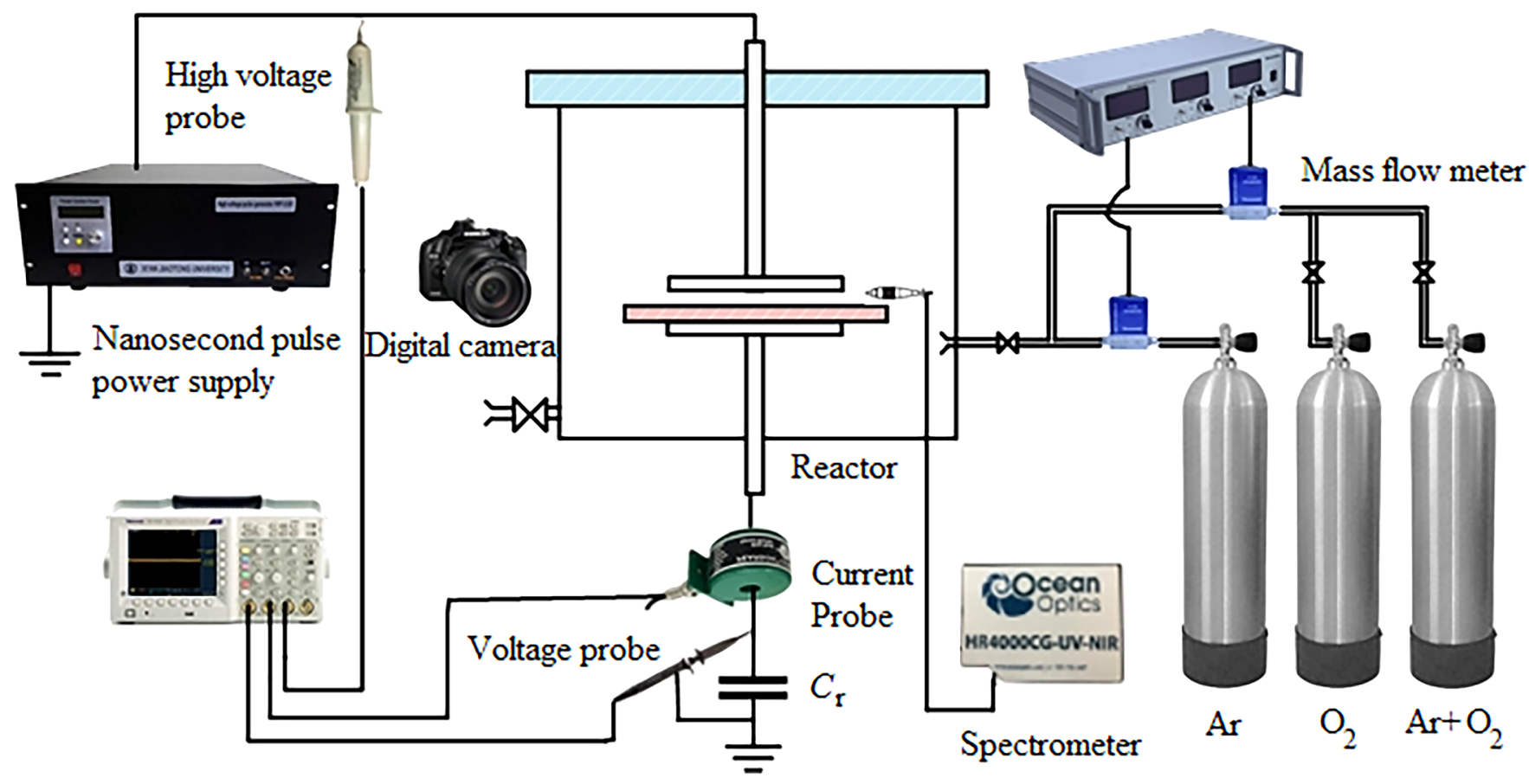

FIG. 1. The experimental setup of the ns pulsed DBD.

does not fill the whole space. The discharge is in the filamentary mode but with dim filaments. With the increase in the voltage to $3.2 \mathrm{kV}$ and $3.25 \mathrm{kV}$, the discharge becomes stronger with the whole space becomes filled with plasma. Interestingly, the number of the observed filaments decreases with the increase in the applied voltage. When the applied voltage is further increased to $3.5 \mathrm{kV}$, it is difficult to distinguish the filaments from the discharge image. At $3.75 \mathrm{kV}, 4 \mathrm{kV}, 4.25 \mathrm{kV}$, and $4.5 \mathrm{kV}$, the discharge is very uniform, while the increased applied voltage just enhances the discharge intensity as evidenced by the higher brightness in the discharge images. With the applied voltage increased to $4.75 \mathrm{kV}$ and
$5 \mathrm{kV}$, there are bright thin filaments appearing in the plasma, which lowers the discharge uniformity.

Although the variation of the discharge can be seen from the observed discharge images, it is hard to compare the discharge uniformity for the discharge images visually. To analyze the discharge dynamic and spatial uniformity, researchers have employed fast Fourier transform, gray-level histogram, spatial correlation function, etc., as image processing methods..$^{19,35,36}$ In our experiment, the discharge images are observed from the side with $1 / 8 \mathrm{~s}$ exposure time. Considering that the filaments bridge the high voltage plate electrode and the dielectric barrier, the middle horizontal line can

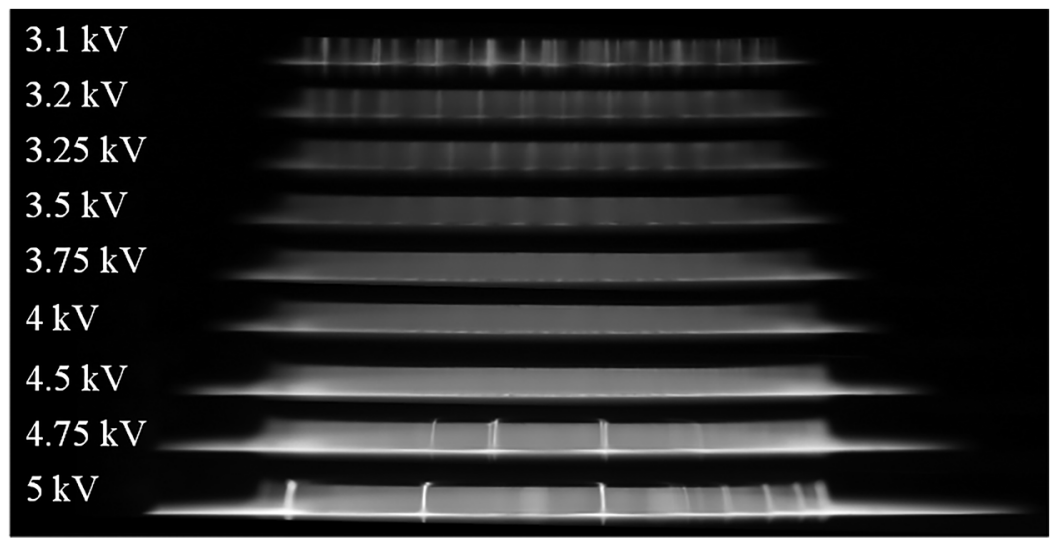

FIG. 2. Discharge images of the ns pulsed Ar DBD at different applied voltages (photo exposure time is $1 / 8 \mathrm{~s}$ ). 
be used to represent the plasma uniformity. Without considering the two-dimensional (2D) uniformity and the periodic pattern of the plasma in space, the image processing method can be simplified and the gray value standard deviation (GVSD) method has been used to quantitatively analyze the plasma uniformity. At first, the gray values of the pixels on the $40 \mathrm{~mm}$ long horizontal line in the middle of the discharge area are obtained by graying processing and divided the length of plasma to get the values of $x_{\mathrm{n}}$. With the averaged value $x_{\mathrm{m}}$ of $x_{\mathrm{n}}$, to standardize the value of the pixels, the zero-mean normalization is obtained from Eq. (1),

$$
\overline{x_{\mathrm{n}}}=\frac{x_{\mathrm{n}}-x_{\mathrm{m}}}{v},
$$

where $\overline{x_{\mathrm{n}}}$ represents the zero-mean normalized pixel value and $v$ is the variance. For the evaluation of discharge uniformity, the gradient value of ${\overline{x_{n}}}^{\prime}$ is obtained by differentiation of $\overline{x_{\mathrm{n}}}$. The standard deviation of $\overline{x_{n}}$, GVSD, is used to represent the uniformity of the discharge.

Figure 3 shows the GVSD of the discharge images of Fig. 2 at different applied voltages from $3.1 \mathrm{kV}$ to $5 \mathrm{kV}$. It can be observed that the GVSD decreases from about 10 at $3.1 \mathrm{kV}$ to about 1.3 at $3.5 \mathrm{kV}$, pointing to an improvement in plasma uniformity and is consistent with the observation from the discharge images. In the voltage range from $3.75 \mathrm{kV}$ to $4.5 \mathrm{kV}$, the values of GVSD are below 1 , representing discharges which are very uniform, which is also seen in the corresponding discharge images. Therefore, for this work, we define a uniform discharge for plasmas with a GVSD value below 1 . With the appearance of bright filaments in discharge images at $4.75 \mathrm{kV}$ and $5 \mathrm{kV}$, the values of GVSD increase to about 3.1 and 6.6, respectively. The values of GVSD are consistent with the variation of the discharge uniformity.

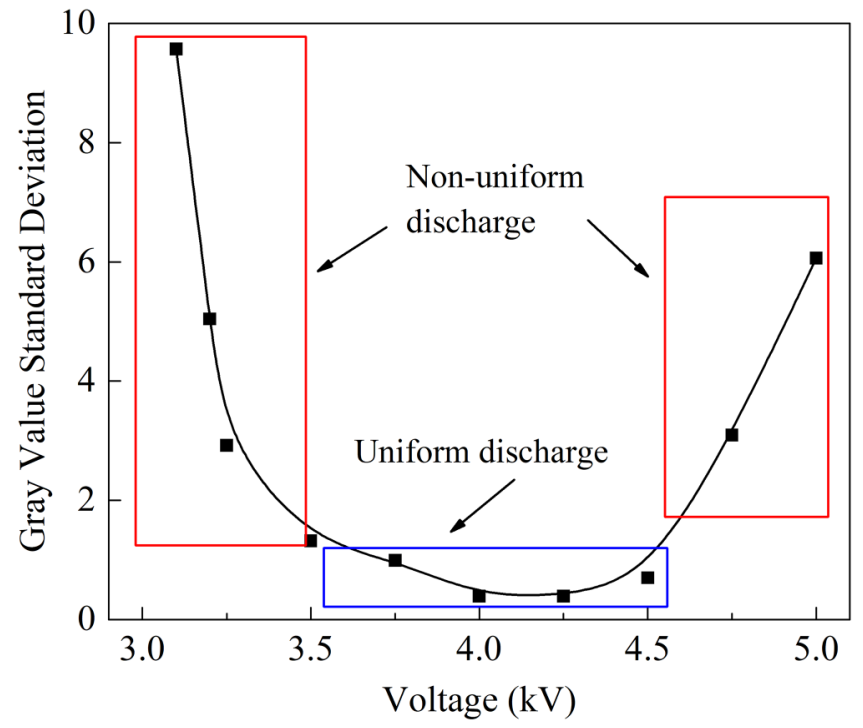

FIG. 3. GVSD of the ns pulsed Ar DBD at different applied voltages.
The effects of the applied voltage on the discharge uniformity can be explained as follows. When the applied voltage is low ( $3.1 \mathrm{kV}$ in our experiment), the electric field strength is low, and the free electrons require a long distance in the gap to obtain sufficient energy to ionize the background gas molecules. It reduces the probability of the formation of electron avalanches. Without sufficiently overlapped electron avalanches channels, the discharge is weak and only fills the space between the electrodes partially with many individual dim filaments.

With the increase in the applied voltage, the electric field is strengthened, and the number of the electron avalanches is increased through more effective collisional ionization. The intensity of the discharge is increased, and with the overlapped electron avalanche channels, the discharge uniformity is improved. Within the voltage range from $3.75 \mathrm{kV}$ to $4.5 \mathrm{kV}$, more electrons are generated, and collisional ionization occurs in the whole space resulting in a uniform discharge mode. When the electric field strength is increased further, it increases the reduced field strength $E / n$ affecting the reaction rates and the Townsend ionization coefficient. A small overvoltage can greatly promote the production of electron avalanches. Therefore, the discharge turns into filamentary mode with bright filaments.

\section{B. Discharge voltage and current estimation}

From the discharge image observation and the GVSD analysis, it can be seen that the applied voltage has profound influence on the discharge uniformity by monitoring the electric field in space. However, for DBDs, the applied voltage $U_{t}$ is composed of the voltage drop across the gap, $U_{\mathrm{g}}$, and the voltage across the dielectric barrier, $U_{\mathrm{d}}$. Correspondingly, the measured current $I_{\mathrm{t}}$ is divided into conduction current through discharge, $I_{\mathrm{g}}$, and displacement current, $I_{\mathrm{d}}$, for the capacitances in DBD. ${ }^{17,37}$ Since $U_{\mathrm{g}}$ determines the reduced electric field, $E / n$, in discharge space and $I_{\mathrm{g}}$ represents the space charges, the variation in $U_{\mathrm{g}}$ and $I_{\mathrm{g}}$ is crucial to reveal the mechanisms of the discharge uniformity and the ignition, development, and extinction process of a DBD.

To obtain $U_{\mathrm{g}}$ and $I_{\mathrm{g}}$ from the measured $U_{\mathrm{t}}$ and $I_{\mathrm{t}}$, a reference capacitor, $C_{r}$, is inserted between the grounded electrode and the ground. The voltage on the reference capacitor $U_{\mathrm{r}}$ should be proportional to $U_{\mathrm{d}}$ since both voltages are across the capacitors. The equivalent electrical circuit is shown in Fig. 4. An amplification coefficient can be selected to estimate $U_{\mathrm{d}}$ by the measured $U_{\mathrm{r}}$ with the method reported in Ref. 17, which assumes that $U_{\mathrm{g}}$ should be near zero when the discharge is extinguished. Therefore, $U_{\mathrm{g}}$ can be obtained by subtracting the estimated $U_{\mathrm{d}}$ from $U_{\mathrm{t}} . U_{\mathrm{t}}, U_{\mathrm{d}}$, and $U_{\mathrm{g}}$ at $3.5 \mathrm{kV}$ and $5 \mathrm{kV}$ are shown in Figs. $5(\mathrm{a})$ and $5(\mathrm{c})$. To extract $I_{\mathrm{g}}$ from $I_{\mathrm{t}}, I_{\mathrm{d}}$ is obtained by pumping the reactor to vacuum with the voltage applied. Without the electrical discharge, the obtained current should be $I_{\mathrm{d}}$. Then, $I_{\mathrm{g}}$ can be obtained by subtracting $I_{\mathrm{d}}$ from $I_{\mathrm{t}}$. Figures $5(\mathrm{~b})$ and $5(\mathrm{~d})$ show $I_{\mathrm{t}}, I_{\mathrm{d}}$, and $I_{\mathrm{g}}$ at $3.5 \mathrm{kV}$ and $5 \mathrm{kV}$, respectively.

It can be seen from Fig. 5 that the peak values of $U_{\mathrm{g}}$ are much smaller than those of $U_{t}$, which is a clear demonstration of the need of voltage separation. The peak moments of $U_{\mathrm{g}}$, about $86 \mathrm{~ns}$ at $3.5 \mathrm{kV}$ and $50 \mathrm{~ns}$ at $5 \mathrm{kV}$, are almost the starting times of $I_{\mathrm{g}}$, about $85 \mathrm{~ns}$ at $3.5 \mathrm{kV}$ and $55 \mathrm{~ns}$ at $5 \mathrm{kV}$. With the increase in $U_{\mathrm{t}}$, 


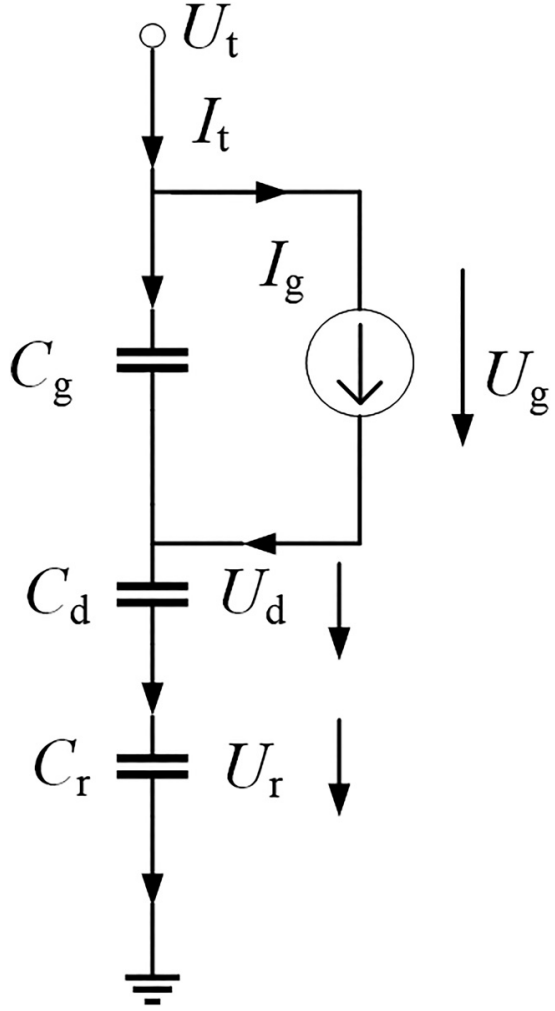

FIG. 4. Equivalent electrical circuit of DBD.

the peak value of $U_{\mathrm{g}}$ increases. The peak moment of $U_{\mathrm{g}}$ also moves forward, which induces early breakdown and higher $I_{\mathrm{g}}$. With the increase in $E / n$, the electron avalanches are accelerated, while the electron migration velocity is also increased. Therefore, it can be noticed that the rising time of the first peak of $I_{\mathrm{g}}$ decreases from about $35 \mathrm{~ns}$ (from $85 \mathrm{~ns}$ to $120 \mathrm{~ns}$ ) at $3.5 \mathrm{kV}$ applied voltage to about $23 \mathrm{~ns}$ (from $55 \mathrm{~ns}$ to $78 \mathrm{~ns}$ ) at $5 \mathrm{kV}$ applied voltage.

Figure 6 shows the peak values of $U_{\mathrm{g}}$ and $I_{\mathrm{g}}$ in the applied voltage ranging from $3.25 \mathrm{kV}$ to $5 \mathrm{kV}$. It can be seen that the $U_{\mathrm{g}}$ increases from about $2.2 \mathrm{kV}$ to $3.5 \mathrm{kV}$, and $I_{\mathrm{g}}$ is not linear to $U_{\mathrm{g}}$ but increases from about $0.5 \mathrm{~A}$ to $5.5 \mathrm{~A}$, which grows much faster than $U_{\mathrm{g}}$. It is because the increase in $U_{\mathrm{g}}$ results in the increase in $E / n$. The $E$ is obtained by the breakdown voltage (peak value of $U_{\mathrm{g}}$ ) dividing the gap distance. The plasma sheath can be formed in atmospheric pressure DBD as a few tens of $\mu \mathrm{m}$ thickness with a few hundreds of $\mathrm{kV} \mathrm{cm}^{-1}$ electric field, ${ }^{38}$ which affects the $E / n$ in space. But the formation cathode sheath in positive pulsed DBD needs more than $10 \mathrm{~ns},{ }^{39}$ and at the breakdown point, it is reasonable to estimate $E / n$ without considering the sheath. With a higher $E / n$, the ionization rate is increased and more electrons are produced. ${ }^{17,40,41}$ The electron drift velocity is also increased, which also contributes to a higher $I_{\mathrm{g}}$. With the promoted electron avalanches, the discharge changes from partial discharge to uniform discharge and then to filaments discharge. Therefore, the discharge uniformity is sensitive to the variation in the amplitude voltage.
Assuming uniform discharge, the electron density, $n_{\mathrm{e}}$, can be estimated from the following equation:

$$
\frac{I_{g}}{S}=e n_{e} V_{d r i f t},
$$

where $S$ is the area of discharge, $e$ is the elementary charge, and $V_{\text {drift }}$ is the drift velocity of electron, which is defined in the following equation:

$$
V_{d r i f t}=\mu_{e} E
$$

where $\mu_{\mathrm{e}}$ is the electron mobility. With the peak values of $U_{\mathrm{g}}$ on gap increasing from $2.15 \mathrm{kV}$ to $3.61 \mathrm{kV}$, the $E / n$ raised from $44 \mathrm{Td}$ to $74 \mathrm{Td}\left(1 \mathrm{Td}=10^{-17} \mathrm{~V} \mathrm{~cm}^{2}\right)$. The electron drift velocity can be obtained by resolving the Boltzmann equation with the BOLSIG+ code over the range of $E / n^{42}$ The $n_{\mathrm{e}}$ is estimated to change from $1.15 \times 10^{17} \mathrm{~m}^{-3}$ to $2.76 \times 10^{17} \mathrm{~m}^{-3}$ with $U_{\mathrm{t}}$ increases from $3.25 \mathrm{kV}$ to $5 \mathrm{kV}$. The estimated $n_{\mathrm{e}}$ is based on the assumption of uniform discharge, and the values of $n_{\mathrm{e}}$ are more accurate for the voltage from $3.75 \mathrm{kV}$ to $4.5 \mathrm{kV}$ with uniform discharge mode. In the filamentary discharge conditions, $n_{\mathrm{e}}$ in filaments is higher and in space is lower than the estimated value.

The variation in electrical parameters also influences the emission spectral characteristics of the Ar DBD. Figure 7 shows the emission spectra recorded at $3.5 \mathrm{kV}$ and $5 \mathrm{kV}$. Figure 8 shows the variation of a group of Ar line intensities on the studied applied voltage ranging from $3.5 \mathrm{kV}$ to $5 \mathrm{kV}$. It can be seen that the intensities of the Ar lines are increased with the increase in the applied voltage, which indicates the increase in $n_{\mathrm{e}}$, and the distributions of the Ar line intensities are also changed for the change in the electron energy distribution, which affects the electron temperature, $T_{\mathrm{e}}$, and plasma-chemical reaction efficiency. The emission intensity, $I$, of direct electron impact excitation Ar, can be given by ${ }^{17}$

$$
I \propto C_{\lambda} A \tau[N] n_{e} k,
$$

where $C_{\lambda}, A$, and $\tau$ are the spectral response of the optical measure system, the Einstein coefficient, and the effective lifetime (related with the quenching processes), respectively; $[N]$ is the number density of the ground state Ar; and $k$ is the excitation rate. Considering the electron energy distribution follows, the Maxwellian function, $T_{\mathrm{e}}$, can be determined by the ratio of the emission intensities with the corresponding excitation rates at specific $E / n$, as shown in the following equation: ${ }^{17}$

$$
\frac{I_{1}}{I_{2}}=\frac{C_{\lambda 1} A_{1} \tau_{1} k_{1}}{C_{\lambda 2} A_{2} \tau_{2} k_{2}}
$$

Without the calibration of spectral response of the optical measure system and the absence of the related quenching rate coefficients and excitation rates, it is difficult to obtain accurate $T_{\mathrm{e}}$ values directly. However, the ratio of the emission intensities with different excited energies can provide the trend of $T_{\mathrm{e}}$. The Ar I $(696.5 \mathrm{~nm})$ and Ar I $(912.3 \mathrm{~nm})$ lines are independent from other lines, and there is approximately a $0.4 \mathrm{eV}$ difference in the excitation energies ( $13.3 \mathrm{eV}$ and $12.9 \mathrm{eV}$, respectively). Therefore, the 

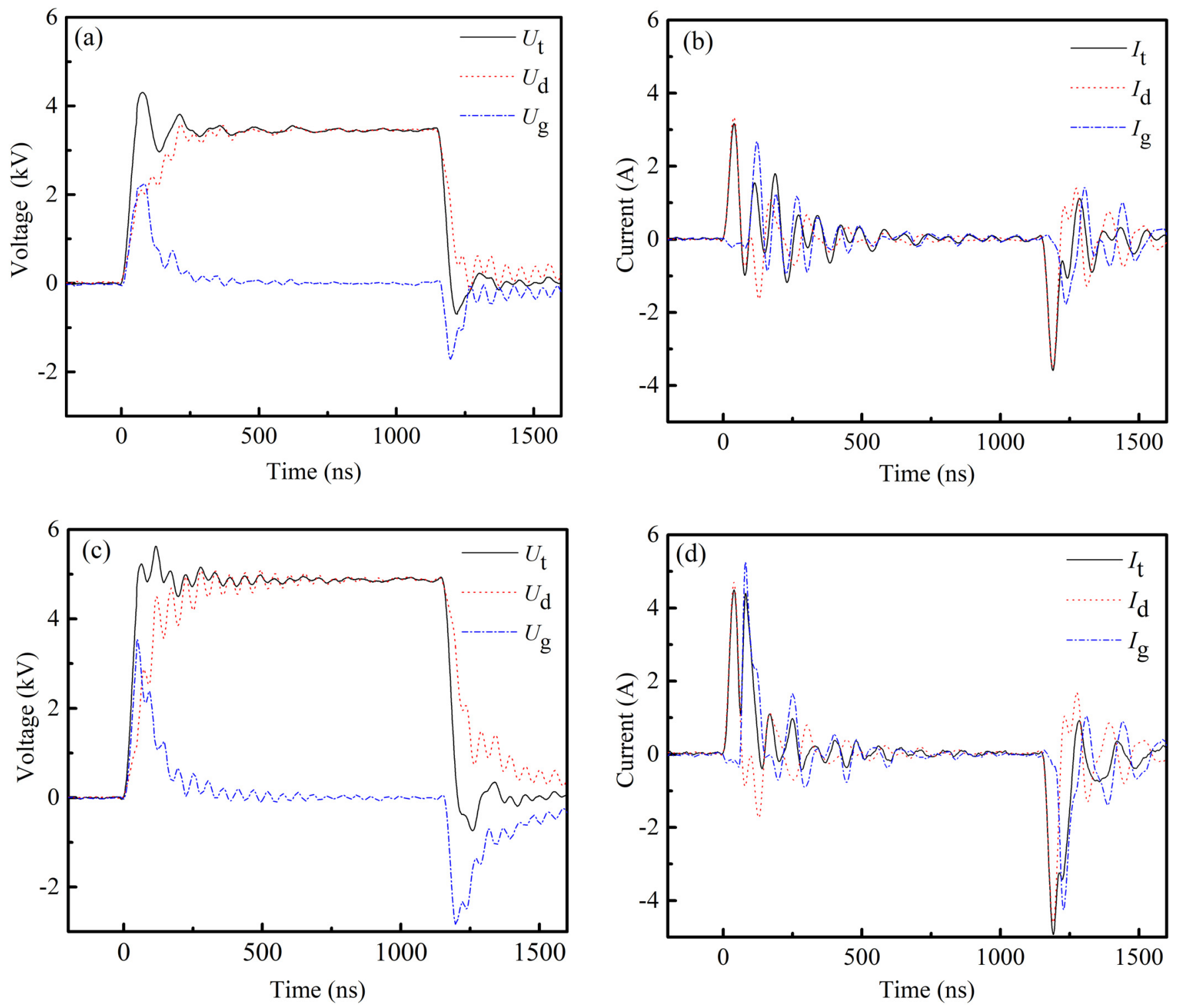

FIG. 5. Discharge gap voltage separation and current separation at $3.5 \mathrm{kV}$ (a) and (b) and $5 \mathrm{kV}$ (c) and (d).

ratio of the emission intensities of Ar I (696.5 nm) and Ar I $(912.3 \mathrm{~nm})$ is selected to indicate the trend of $T_{\mathrm{e}}$ at different applied voltages, which is shown in Fig. 9.

From Fig. 9, it can be seen that with the increase in applied voltage, the ratio of the intensities of Ar I $(696 \mathrm{~nm})$ and Ar I $(912 \mathrm{~nm})$ is increased. Considering the excitation energy of Ar I $(696 \mathrm{~nm}), 13.3 \mathrm{eV}$, is higher than that of $\mathrm{Ar} \mathrm{I}(696 \mathrm{~nm}), 12.9 \mathrm{eV}$, it means more high energy electrons than low energy electrons are produced and $T_{\mathrm{e}}$ is increased. When the applied voltage reaches $4.25 \mathrm{kV}$, the ratio becomes saturated. It is because with the increase in the applied voltage and $E / n$, electrons gain more energy in space and $T_{\mathrm{e}}$ is increased correspondingly. However, with the further increase in the applied voltage, more electrons are generated with higher ionization rate, and there are also strong electrical field distortions in space, which affects the further acceleration of elections and forms filaments. $T_{\mathrm{e}}$ of the electrons in whole space becomes saturated.

\section{Effect of oxygen addition on discharge uniformity}

$\mathrm{Ar}$ is an inert gas, and there is a lack of plasma chemical activity in pure Ar discharges. $\mathrm{O}_{2}$ is added in Ar DBD to increase the 


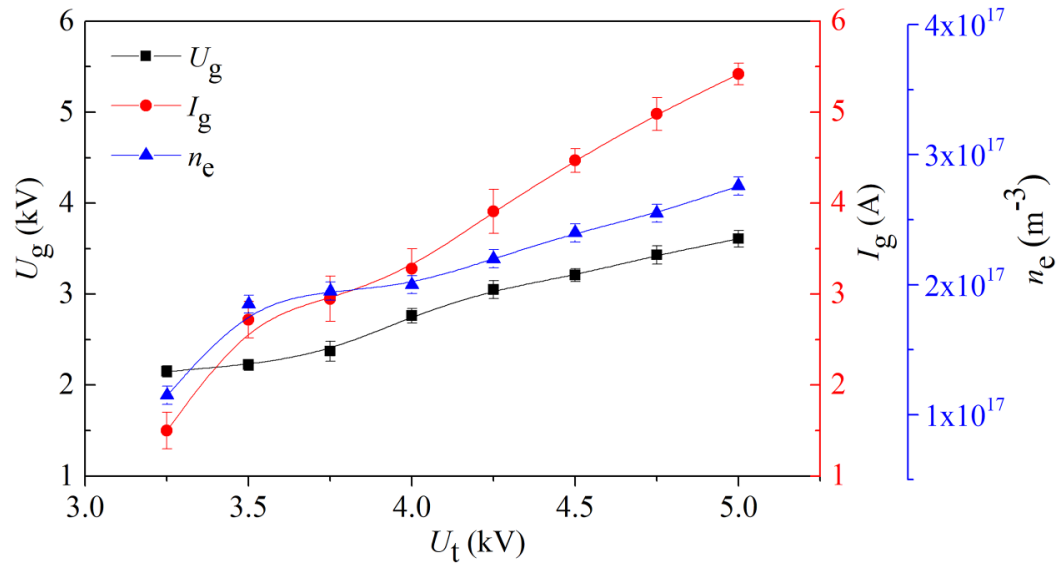

FIG. 6. The peak values of $U_{g}$ and $I_{g}$ with varying applied voltages. plasma oxidative ability for practical applications. The discharge characteristics after oxygen addition are investigated. Figure 10 shows the discharge images of Ar DBD at $4 \mathrm{kV}$ with different $\mathrm{O}_{2}$ contents. It can be seen that the addition of $\mathrm{O}_{2}$ affects the discharge uniformity profoundly. At a small $\mathrm{O}_{2}$ content below $0.1 \%$, the discharge shows uniformity. With a higher $\mathrm{O}_{2}$ content, the discharge becomes non-uniform and nearly distinguished.

To analyze the effect of $\mathrm{O}_{2}$ addition on the plasma uniformity of Ar DBD quantitatively, the GVSDs of the Ar DBD at $4 \mathrm{kV}$, $4.25 \mathrm{kV}$, and $4.5 \mathrm{kV}$ with different $\mathrm{O}_{2}$ contents are calculated and presented in Fig. 11. It can be seen that at a lower $\mathrm{O}_{2}$ contents, the Ar DBD at $4 \mathrm{kV}, 4.25 \mathrm{kV}$, and $4.5 \mathrm{kV}$ remain in a uniform mode with GVSD values below 1 . When the $\mathrm{O}_{2}$ content increases, the GVSD values peak indicates poor discharge uniformity. This behavior is because $\mathrm{O}_{2}$ is an electronegative gas, where electrons can attach and form $\mathrm{O}_{2}^{-}$ions. The electron attachments and $\mathrm{O}_{2}^{-}$ ions in space would distort the space electric field and promote the formation of filaments, which results in the rising of GVSD and

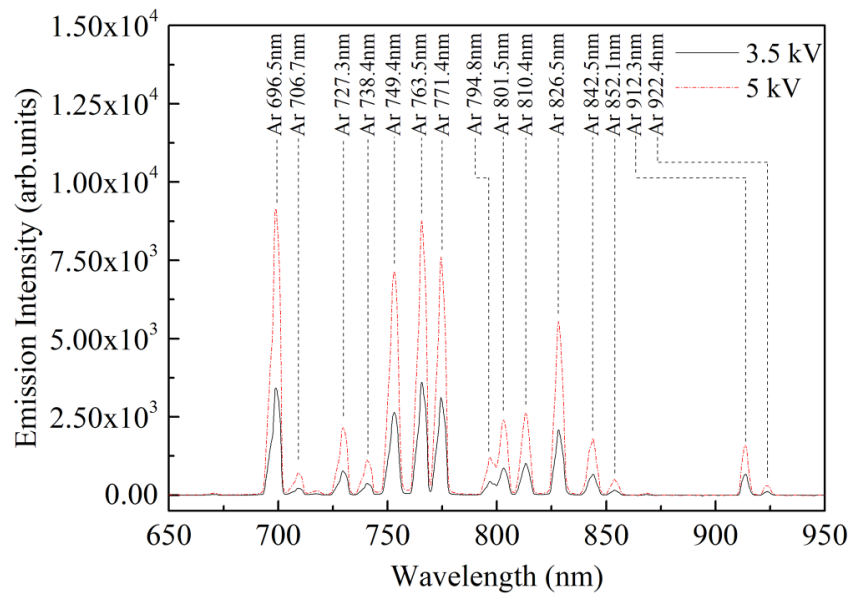

FIG. 7. The emission spectra of Ar DBD at $3.5 \mathrm{kV}$ and $5 \mathrm{kV}$. non-uniform discharge,

$$
\begin{gathered}
\mathrm{e}+\mathrm{O}_{2} \rightarrow \mathrm{O}_{2}^{-}, \\
\mathrm{e}+\mathrm{O}_{2}+\mathrm{M} \rightarrow \mathrm{O}_{2}^{-}+\mathrm{M},
\end{gathered}
$$

where $\mathrm{M}$ is either Ar or $\mathrm{O}_{2}$ molecule. With the further increase in $\mathrm{O}_{2}$ content, the number of free electrons decreases, and there are no enough electron avalanches formed in space. The discharge fills the space partially with many individual dim filaments and the breakdown voltage increases correspondingly. It is also noted that the GVSDs of $4.5 \mathrm{kV}$ and $4.25 \mathrm{kV}$ show more clear peaks than the GVSD of $4 \mathrm{kV}$. It is because that the $E / n$ of $4.5 \mathrm{kV}$ and $4.25 \mathrm{kV}$ is higher than that of $4 \mathrm{kV}$. With the addition of $\mathrm{O}_{2}$, the filaments and the electrical field distortion are more evident and appear at a lower $\mathrm{O}_{2}$ content. Therefore, there is a higher peak in the GVSD

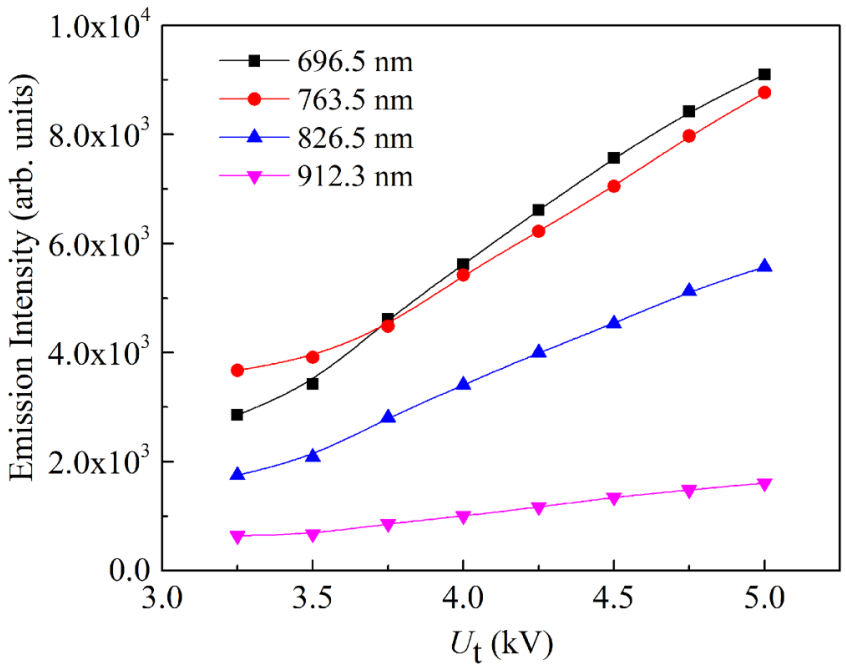

FIG. 8. The selected Ar emission lines intensities at different applied voltages. 


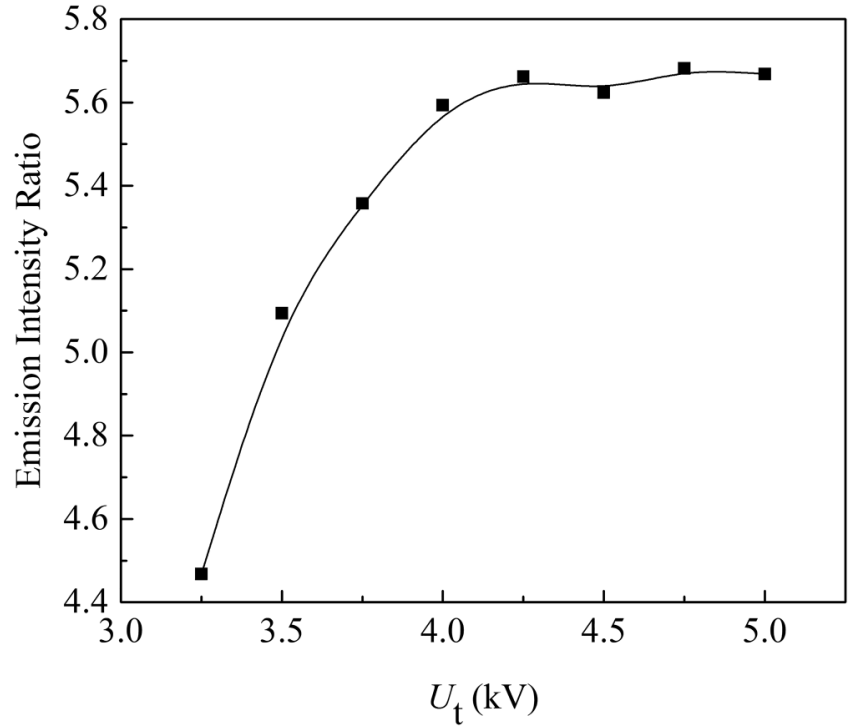

FIG. 9. The ratio of emission intensities of Ar I $(696 \mathrm{~nm})$ and $\mathrm{Ar} \mathrm{I}(912 \mathrm{~nm})$ at different applied voltages.

values for the higher voltages than that of lower voltages at a lower $\mathrm{O}_{2}$ content.

To further investigate the effect of $\mathrm{O}_{2}$ addition on the electrical characteristics of the Ar DBD, $U_{\mathrm{g}}$ and $I_{\mathrm{g}}$ are calculated at $4.5 \mathrm{kV}$ with $0.1 \%-10 \% \mathrm{O}_{2}$ content, which are shown in Fig. 12. $n_{\mathrm{e}}$ is also estimated with Eq. (2) and the separated $U_{\mathrm{g}}$ and $I_{\mathrm{g}}$ with uniform discharge assumption. It can be seen that with a small amount $\mathrm{O}_{2}$ addition (from $0.1 \%$ to $0.4 \%$ ), $U_{\mathrm{g}}$ decreases slightly, which corresponds to the filament discharge stage. This means the filament channels bridge the electrodes and release the electric power. $n_{\mathrm{e}}$ is

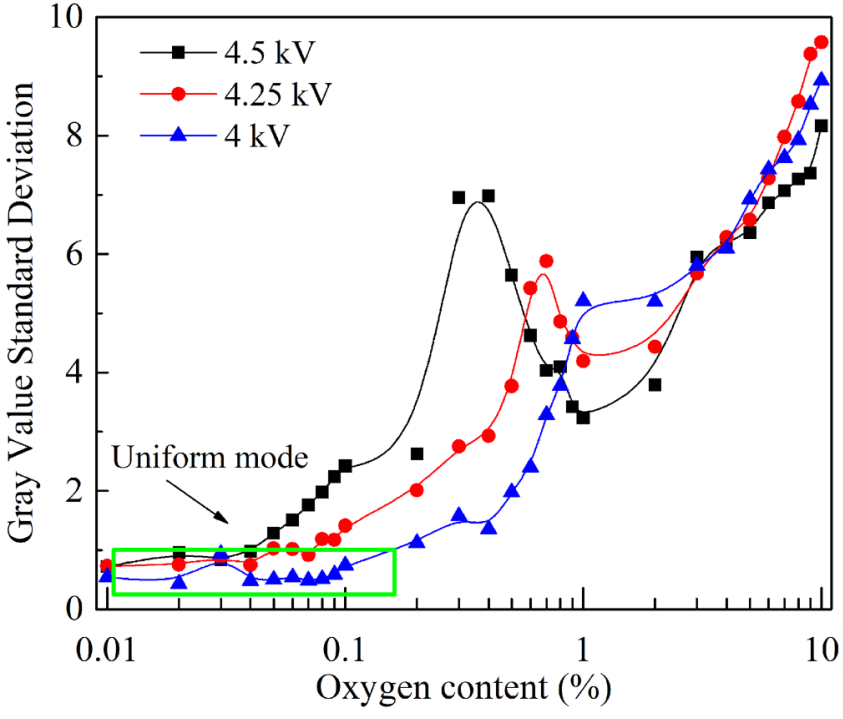

FIG. 11. GVSD of the $\operatorname{Ar} D B D$ at $4 \mathrm{kV}, 4.25 \mathrm{kV}$, and $4.5 \mathrm{kV}$ with different $\mathrm{O}_{2}$ contents.

also increased from $0.1 \%$ to $0.4 \% \mathrm{O}_{2}$ addition, which shows the promotion of the production of free electrons with small amount $\mathrm{O}_{2}$ addition especially with $U_{\mathrm{g}}$ decreased in the meantime. With more $\mathrm{O}_{2}$ added, to about $1 \%, U_{\mathrm{g}}$ maintains at a high level for the less conductivity of the filament channels for the $\mathrm{O}_{2}^{-}$ions generation with the attachment of electrons on $\mathrm{O}_{2}$. With the $\mathrm{O}_{2}$ content increasing from $1 \%$ to $4 \%$, more charged particles of $\mathrm{O}_{2}^{-}$fill the space and a larger proportion of the applied voltage applied across the dielectric barrier other than the gas gap, which induces the slight decrease in $U_{\mathrm{g}}$. But $n_{\mathrm{e}}$ is still maintaining in high level at

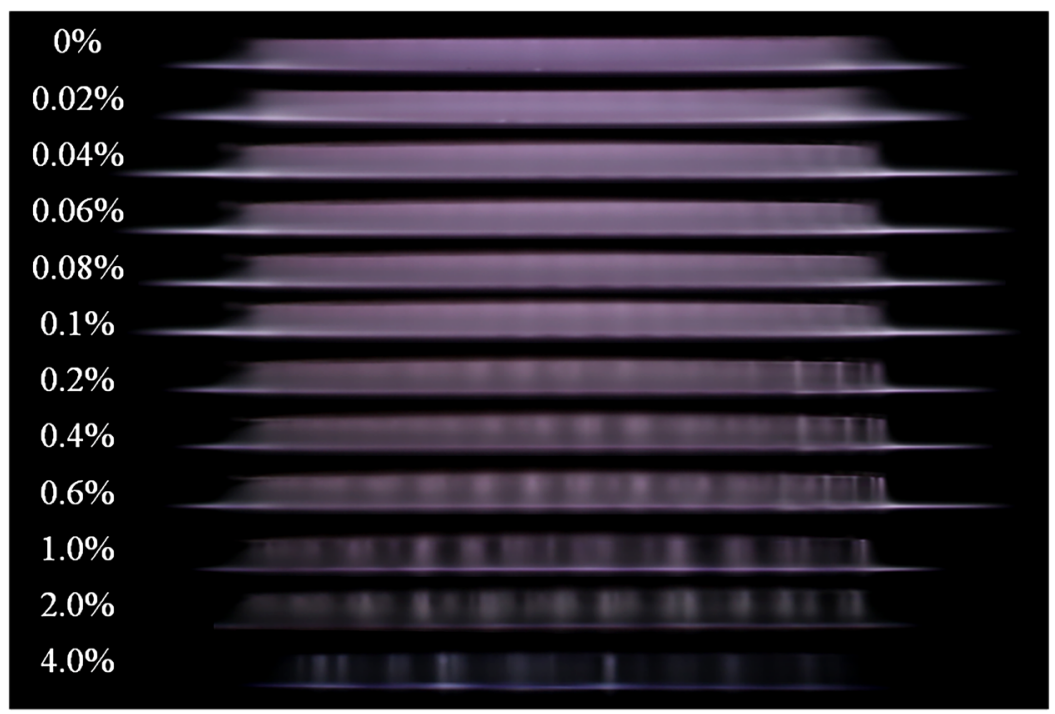

FIG. 10. Discharge images of the Ar DBD at $4 \mathrm{kV}$ with different $\mathrm{O}_{2}$ contents (photo exposure time is $1 / 8 \mathrm{~s}$ ). 


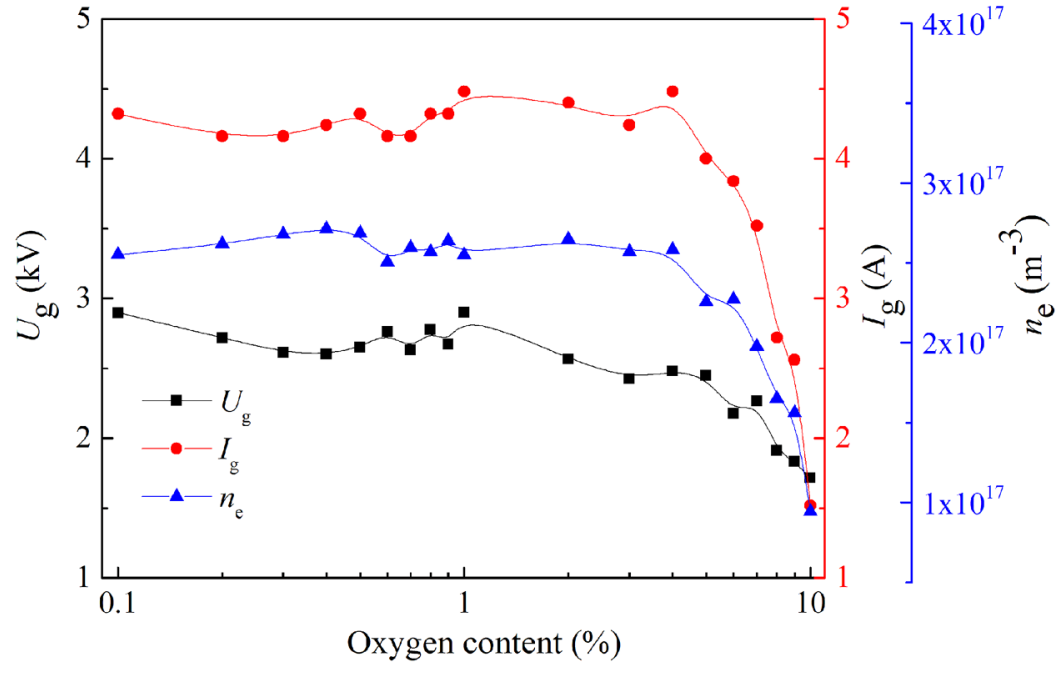

FIG. 12. The peak values of $U_{g}$ and $I_{g}$ and the estimated $n_{\mathrm{e}}$ with different $\mathrm{O}_{2}$ contents. about $2.5 \times 10^{-17} \mathrm{~m}^{-3}$. With further $\mathrm{O}_{2}$ addition, the discharge goes toward extinguishment with lack of free electrons and drop of $U_{\mathrm{g}}$. Then, $I_{\mathrm{g}}$ and $n_{\mathrm{e}}$ drop significantly. It is noticed from the curves of $I_{\mathrm{g}}$ and $n_{\mathrm{e}}$ that the dropped proportion of $I_{\mathrm{g}}$ is larger than that of $n_{\mathrm{e}}$, which indicates the drop of mobility and drift velocity. The reason is the more $\mathrm{O}_{2}^{-}$ions generation. ${ }^{43}$ It is worth noting that the estimated $n_{\mathrm{e}}$ is more accurate in the uniform discharge mode with $\mathrm{O}_{2}$ content below $1 \%$ and for higher $\mathrm{O}_{2}$ content DBDs with filamentary discharge conditions, $n_{\mathrm{e}}$ in filaments is higher and in space is lower than the estimated value.

The addition of $\mathrm{O}_{2}$ also affects the emission spectra of the $\mathrm{Ar}$ DBD as shown in Fig. 13 with $0.1 \%$ and $1 \%$ oxygen contents. Figure 14 shows the variation of a group of Ar line intensities on the studied $\mathrm{O}_{2}$ content ranging from $0.1 \%$ to $10 \%$. It can be seen from those figures that the emission intensities of the Ar lines are decreased significantly with the increase in the $\mathrm{O}_{2}$ content, which indicates the decrease in $n_{\mathrm{e}}$. Compared with the variation of $I_{\mathrm{g}}$ in Fig. 12, the emission intensities of Ar lines in Fig. 14 drop almost $80 \%$, but $I_{\mathrm{g}}$ remains almost constant for oxygen contents from $0.1 \%$ to about $4 \%$. This observation suggests that the electrons are attached with $\mathrm{O}_{2}$ to form $\mathrm{O}_{2}^{-}$ions and the drop of the electron energy. When the $\mathrm{O}_{2}$ content is increased further, the discharge becomes weak, and the emission intensities of Ar lines and $I_{\mathrm{g}}$ decrease. The distributions of the Ar line intensities are also changed, which represent the change in $T_{\mathrm{e}}$. The ratio of the intensities of Ar I $(696.5 \mathrm{~nm})$ and Ar I $(912.3 \mathrm{~nm})$ is also used to indicate the variation of $T_{\mathrm{e}}$ with different $\mathrm{O}_{2}$ contents, which is shown in Fig. 15.

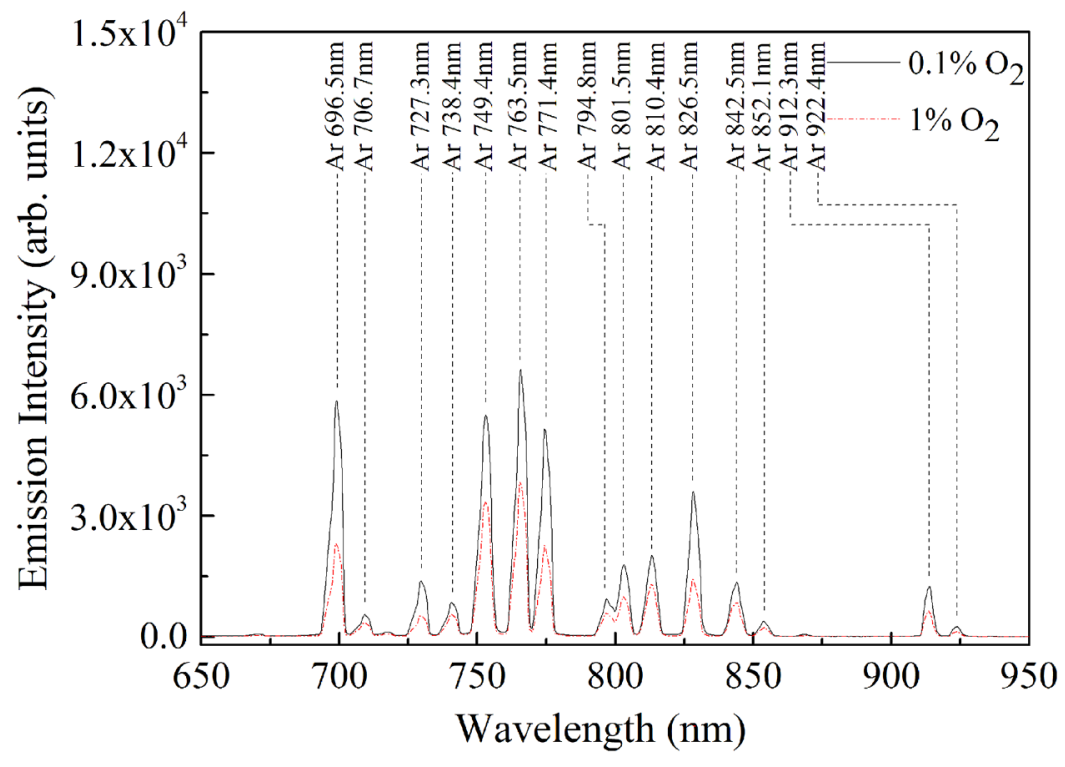

FIG. 13. The emission spectra of $\mathrm{Ar} \mathrm{DBD}$ at $4.5 \mathrm{kV}$ with $0.1 \%$ and $1 \% \mathrm{O}_{2}$ contents. 


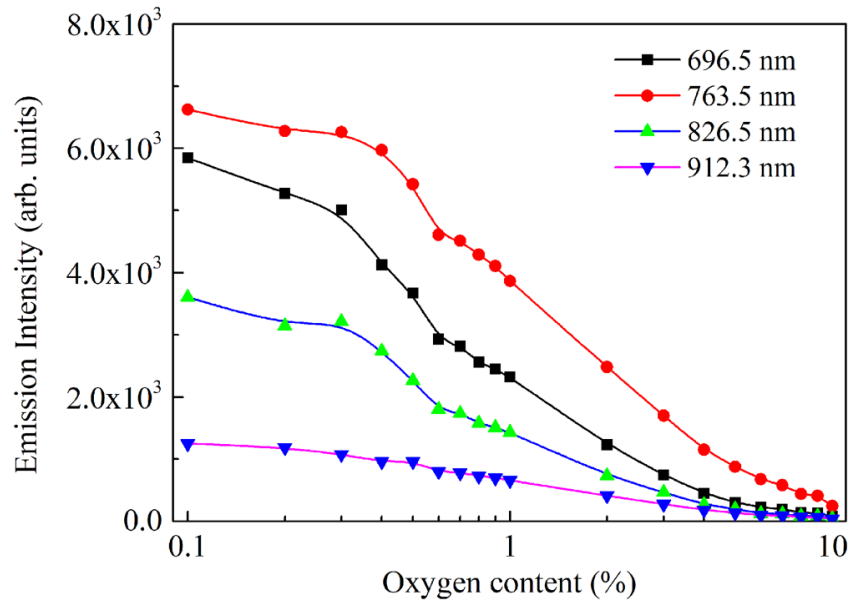

FIG. 14. The selected Ar emission lines intensities at different $\mathrm{O}_{2}$ contents.

From Fig. 15, it can be seen that with the increase in $\mathrm{O}_{2}$ content from $0.1 \%$ to $10 \%$, the ratio of the intensities of Ar I $(696 \mathrm{~nm})$ and Ar I $(912 \mathrm{~nm})$ is decreased. For the threshold, the energy of the upper state of Ar I $(696.5 \mathrm{~nm})$ is higher than that of Ar I $(912.3 \mathrm{~nm})$, indicating that fewer high energy electrons are produced and $T_{\mathrm{e}}$ is decreased. This may result from the reduction of the electron mean free path with the $\mathrm{O}_{2}$ addition, which limits the energy the electrons gain from the electric field.

The addition of $\mathrm{O}_{2}$ can increase the plasma chemical activity by producing a range of reactive species such as $\mathrm{O}, \mathrm{O}_{3}$, etc. With the observation of the emission spectra of $\mathrm{DBD}$, the effect of $\mathrm{O}_{2}$

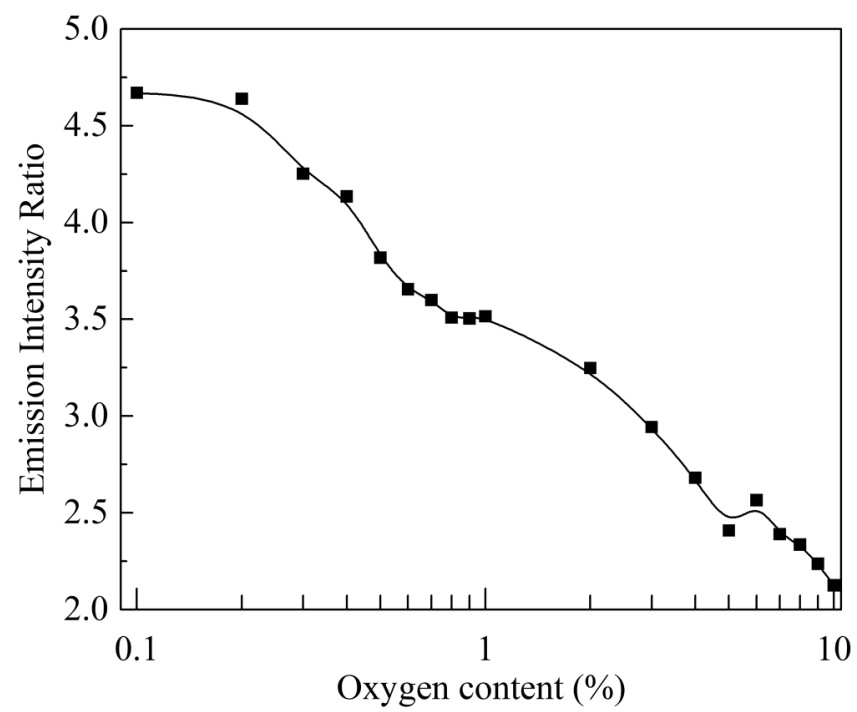

FIG. 15. The ratio of emission intensities of $\operatorname{Ar~I~}(696 \mathrm{~nm})$ and $\mathrm{Ar} I(912 \mathrm{~nm})$ at different $\mathrm{O}_{2}$ contents.

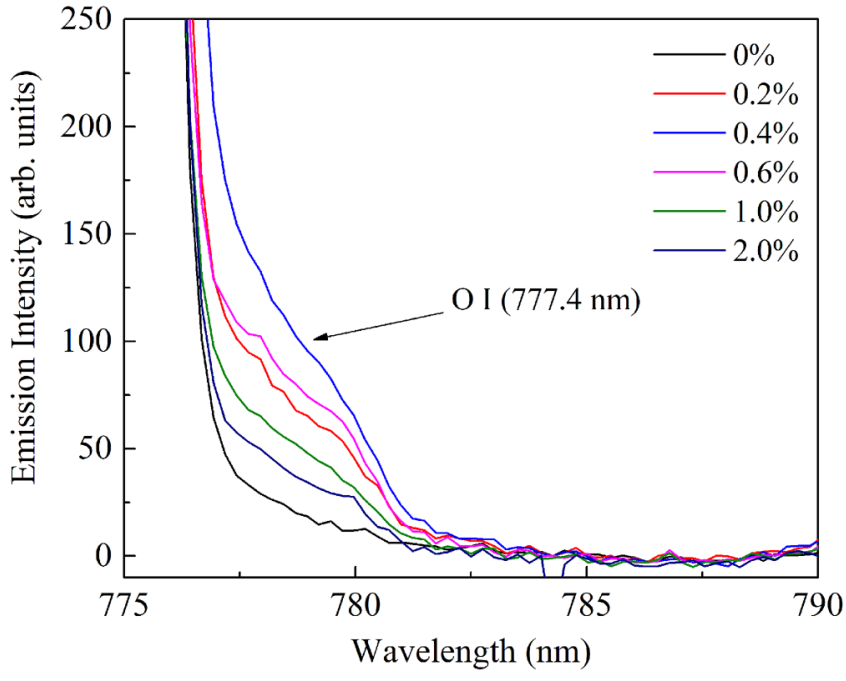

FIG. 16. O I $(777 \mathrm{~nm})$ emission line intensities at different $\mathrm{O}_{2}$ contents.

content on the $\mathrm{O}$ emission can be obtained. Figure 16 shows the emission spectra of O I $(777.4 \mathrm{~nm})$ at $4.5 \mathrm{kV}$ with different oxygen contents. It can be observed that the O I $(777.4 \mathrm{~nm})$ emission line appears when the $\mathrm{O}_{2}$ is added to the Ar DBD. But O I (777.4 nm) is very weak and overlapped with the nearby Ar emission. It is because the production of the upper state $\mathrm{O}\left(3 \mathrm{p}^{5} \mathrm{P}\right)$ of $\mathrm{O} I$ $(777.4 \mathrm{~nm})$ need higher energy than the surrounding Ar emission lines, which transmit from the upper $4 \mathrm{p}$ states with excitation energy around $13 \mathrm{eV}$. The production of $\mathrm{O}$ ground state atom from reactions (8) and (9) needs $5.1 \mathrm{eV}$ and $3.6 \mathrm{eV}$, respectively, ${ }^{44}$ and the excitation of $\mathrm{O}\left(3 \mathrm{p}^{5} \mathrm{P}\right)$ needs $10.7 \mathrm{eV}$. Considering the small amount of $\mathrm{O}_{2}$ molecular and $\mathrm{O}$ atom, the $\mathrm{O}\left(3 \mathrm{p}^{5} \mathrm{P}\right)$ is mainly produced by direct electron impact dissociation excitation, which needs $15.8 \mathrm{eV}$ or $14.3 \mathrm{eV}$. Therefore, the $\mathrm{O}$ emission is much weaker than the Ar emissions,

$$
\begin{gathered}
\mathrm{e}+\mathrm{O}_{2} \rightarrow \mathrm{e}+\mathrm{O}+\mathrm{O}, \\
\mathrm{e}+\mathrm{O}_{2} \rightarrow \mathrm{O}+\mathrm{O}^{-} .
\end{gathered}
$$

For the weak and overlapped $\mathrm{O}$ emission line, it is hard to analyze the effect of $\mathrm{O}_{2}$ content on the $\mathrm{O}$ I $(777.4 \mathrm{~nm})$ emission intensity quantitatively. However, from Fig. 16, the tendency of the $\mathrm{O}$ emission at different $\mathrm{O}_{2}$ contents can be seen, qualitatively. The addition of $\mathrm{O}_{2}$ promotes the $\mathrm{O} \mathrm{I}(777.4 \mathrm{~nm})$ emission at first and the $\mathrm{O}$ I $(777.4 \mathrm{~nm})$ emission line intensity shows a maximum at $0.4 \% \mathrm{O}_{2}$ content. With the $\mathrm{O}_{2}$ content further increased, the $\mathrm{O} \mathrm{I}$ $(777.4 \mathrm{~nm})$ emission line intensity drops. It is because that the upper state $\mathrm{O}\left(3 \mathrm{p}^{5} \mathrm{P}\right)$ of $\mathrm{O} \mathrm{I}(777.4 \mathrm{~nm})$ is produced by direct electron impact dissociation excitation. With the increasing $\mathrm{O}_{2}$ content, the O I $(777.4 \mathrm{~nm})$ emission intensity increases correspondingly. But with more $\mathrm{O}_{2}$ addition, $n_{\mathrm{e}}$ and $T_{\mathrm{e}}$ decrease. Although there is an increase in the number density of $\mathrm{O}_{2}$, the electrons with energies higher than the threshold for the dissociation excitation reaction 
are greatly reduced, which results in the decrease in the emission intensity of the $\mathrm{O}$ emission.

\section{CONCLUSIONS}

In this paper, an Ar DBD is driven by an ns pulsed power supply, and the influence of the pulsed voltage on the discharge uniformity was investigated using optical and electrical measurements. Using the GVSD quantitative analysis, it is found the DBD changes from a non-uniform discharge to uniform discharge (values of GVSD below 1), and then non-uniform discharges with bright filaments. The addition of $\mathrm{O}_{2}$ causes a filament discharge with high $E / n$ and quenches the discharge leading to higher GVSD values. The separation of the applied voltage and measured current shows that the voltage across the gap, $U_{\mathrm{g}}$, and the discharge current, $I_{\mathrm{g}}$, increase with the increases in the applied voltage. $I_{\mathrm{g}}$ increases faster than $U_{\mathrm{g}}$ for a higher $E / n$ favoring ionization processes and electron migration. The discharge uniformity is sensitive to the variation in the voltage. With increasing $\mathrm{O}_{2}$ content, $U_{\mathrm{g}}$ shows a decrease, but $I_{\mathrm{g}}$ and $n_{\mathrm{e}}$ maintain high values for $\mathrm{O}_{2}$ content ranging from $0.1 \%$ to $4 \%$. $n_{\mathrm{e}}$ shows a maximum value of $2.7 \times 10^{-17} \mathrm{~m}^{-3}$ at $0.4 \% \mathrm{O}_{2}$ content. When the $\mathrm{O}_{2}$ content exceeds $4 \%$, a larger proportion of the applied voltage applies to the dielectric barrier rather than the gas gap, and $I_{\mathrm{g}}$ also drops significantly. The larger drop of $I_{\mathrm{g}}$ than $n_{\mathrm{e}}$ indicates the drop of drift velocity and more $\mathrm{O}_{2}^{-}$ions generation. The emission intensities of Ar lines increase with increasing applied voltage and decrease with the increasing of $\mathrm{O}_{2}$ content. The ratio of the emission intensities of $\mathrm{Ar}$ I $(696.5 \mathrm{~nm})$ and Ar I $(912.3 \mathrm{~nm})$ can be used to indicate the electron temperature, $T_{\mathrm{e}}$, of the Ar DBD, which decreases with increasing $\mathrm{O}_{2}$ content, while it becomes higher with the voltage rising from $3.1 \mathrm{kV}$ to $4.25 \mathrm{kV}$ and then becomes saturated. The $\mathrm{O} \mathrm{I}$ $(777.4 \mathrm{~nm})$ emission intensity shows a maximum at $0.4 \% \quad \mathrm{O}_{2}$ content. The experimental results contribute to the improvement of discharge uniformity and plasma chemical reactivity, which are important for a diverse range of practical applications.

\section{ACKNOWLEDGMENTS}

This work was supported by the National Nature Science Foundation (No. 51777091), the Primary Research and Development Plan of Jiangsu Province (No. BE2017023), and the Postgraduate Research \& Practice Innovation Program of Jiangsu Province (No. SJCX20_0345).

\section{DATA AVAILABILITY}

The data that support the findings of this study are available from the corresponding author upon reasonable request.

\section{REFERENCES}

${ }^{1}$ W. Xiong, Q. Guo, Z. Guo, H. Li, R. Zhao, Q. Chen, Z. Liu, and X. Wang, J. Mater. Chem. A 6, 4297-4304 (2018).

${ }^{2}$ K. J. Kanarik, S. Tan, and R. A. Gottscho, J. Phys. Chem. Lett. 9, 4814-4821 (2018).

${ }^{3}$ Z. Bo, Y. Tian, Z. J. Han, S. Wu, S. Zhang, J. Yan, K. Cen, and K. Ostrikov, Nanoscale Horiz. 2, 89-98 (2017).

${ }^{4}$ U. Cvelbar, Z. Chen, I. Levchenko, R. M. Sheetz, J. B. Jasinski, M. Menon, M. K. Sunkara, and K. Ostrikov, Chem. Commun. 48, 11070 (2012).
${ }^{5}$ X. Fang, C. Corbella, D. B. Zolotukhin, and M. Keidar, Front. Chem. Sci. Eng. 13, 350-359 (2019).

${ }^{6}$ F. Fanelli and F. Fracassi, Surf. Coat. Tech. 322, 174-201 (2017).

${ }^{7}$ B. Ashford, Y. Wang, C.-K. Poh, L. Chen, and X. Tu, App. Catal. B Environ. 276, 119110 (2020).

${ }^{8}$ L. Wang, Y. Yi, C. Wu, H. Guo, and X. Tu, Angew. Chem. Int. Edit. 56, 13679-13683 (2017).

${ }^{9}$ B. Huang, C. Zhang, H. Bai, S. Zhang, K. Ostrikov, and T. Shao, Chem. Eng. J. 396, 125185 (2020).

${ }^{10}$ H. Liang, F. Ming, and H. N. Alshareef, Adv. Energy. Mater. 8, 1801804 (2018).

${ }^{11}$ R. Zhou, R. Zhou, Y. Xian, Z. Fang, X. Lu, K. Bazaka, A. Bogaerts, and K. Ostrikov, Chem. Eng. J. 382, 122745 (2020).

${ }^{12}$ P. J. Bruggeman, F. Iza, and R. Brandenburg, Plasma Sources Sci. Technol. 26, 123002 (2017).

${ }^{13}$ R. Brandenburg, Plasma Sources Sci. Technol. 26, 053001 (2017).

${ }^{14}$ D.-Z. Yang, Y. Yang, S.-Z. Li, D.-X. Nie, S. Zhang, and W.-C. Wang, Plasma Sources Sci. Technol. 21, 035004 (2012).

${ }^{15}$ S. Tao, L. Kaihua, Z. Cheng, Y. Ping, Z. Shichang, and P. Ruzheng, J. Phys. D Appl. Phys. 41, 215203 (2008).

${ }^{16}$ C. Liu, D. Dobrynin, and A. Fridman, J. Phys. D Appl. Phys. 47, 252003 (2014).

${ }^{17}$ F. Liu, G. Huang, and B. Ganguly, Plasma Sources Sci. Technol. 19, 045017 (2010).

${ }^{18}$ C. Zhang, T. Shao, H. Ma, D. Zhang, C. Ren, P. Yan, T. Victor, and S. Edl, IEEE Trans. Dielectr. Electr. Insul. 20, 1304-1314 (2013).

${ }^{19}$ Q. Ye, D. Yu, F. Yang, and D. Tan, IEEE Trans. Plasma Sci. 41, 540-544 (2013).

${ }^{20}$ L. Dosoudilová, R. Tschiersch, M. Bogaczyk, Z. Navrátil, H.-E. Wagner, and D. Trunec, J. Phys. D Appl. Phys. 48, 355204 (2015).

${ }^{21}$ D. Liu, B. Sun, F. Iza, D. Xu, X. Wang, M. Rong, and M. G. Kong, Plasma Sources Sci. Technol. 26, 045009 (2017).

${ }^{22}$ Y. Du, G. Nayak, G. Oinuma, Z. Peng, and P. J. Bruggeman, J. Phys. D Appl. Phys. 50, 145201 (2017).

${ }^{23}$ R. Brandenburg, V. A. Maiorov, Y. B. Golubovskii, H. E. Wagner, J. Behnke, and J. F. Behnke, J. Phys. D Appl. Phys. 38, 2187-2197 (2005).

${ }^{24}$ M.-L. Hicks, A. C. Pakpour-Tabrizi, V. Zuerbig, L. Kirste, C. Nebel, and R. B. Jackman, J. Appl. Phys. 125, 244502 (2019).

${ }^{25}$ R. Tschiersch, S. Nemschokmichal, and J. Meichsner, Plasma Sources Sci. Technol. 25, 025004 (2016).

${ }^{26}$ R. Bazinette, R. Subileau, J. Paillol, and F. Massines, Plasma Sources Sci. Technol. 23, 035008 (2014).

${ }^{27}$ C. Jiang and C. Carter, Plasma Sources Sci. Technol. 23, 065006 (2014).

${ }^{28}$ Z. Fang, T. Shao, R. Wang, J. Yang, and C. Zhang, Eur. Phys. J. D 70, 79 (2016).

${ }^{29}$ H. Pang, Q. Chen, B. Li, F. Fei, and S. Yang, IEEE Trans. Plasma Sci. 39, 1689-1694 (2011).

${ }^{30}$ J. Yang, C. Tian, L. Wang, T. Tan, J. Yin, B. Wang, and H. Fu, ChemPlusChem 77, 301-307 (2012).

${ }^{31}$ C. Kohn, O. Chanrion, and T. Neubert, Plasma Sources Sci. Technol. 26, 015006 (2017).

${ }^{32}$ Y. Liu, S. A. Starostin, F. J. J. Peeters, M. C. M. van de Sanden, and H. W. de Vries, J. Phys. D Appl. Phys. 51, 114002 (2018).

${ }^{33}$ S. Espinbo, S. Hofmann, J. M. Palomares, and S. Nijdam, Plasma Sources Sci. Technol. 26, 105008 (2017).

${ }^{34}$ S. Liu and M. Neiger, J. Phys. D Appl. Phys. 36, 3144-3150 (2003).

${ }^{35}$ M. Rong, D. Liu, D. Wang, B. Su, X. Wang, and Y. Wu, IEEE Trans. Plasma Sci. 38, 966-972 (2010).

${ }^{36}$ Y. Zhang, J. Li, N. Lu, K. Shang, A. Mizuno, and Y. Wu, Vacuum 123, 49-53 (2016).

${ }^{37}$ C. Miao, F. Liu, Q. Wang, M. Cai, and Z. Fang, Eur. Phys. J. D 72, 57 (2018).

${ }^{38}$ B. Y. Babaeva and M. J. Kushner, Plasma Sources Sci. Technol. 20, 035017 (2011). 
${ }^{39}$ C. Sang, J. Sun, and D. Wang, J. Phys. D Appl. Phys. 43, 045202 (2010).

${ }^{40}$ A. Hösl, P. Häfliger, and C. M. Franck, J. Phys. D Appl. Phys. 50, 485207 (2017).

${ }^{41}$ J. B. Franek, S. H. Nogami, V. I. Demidov, M. E. Koepke, and E. V. Barnat, Plasma Sources Sci. Technol. 24, 034009 (2015).
${ }^{42}$ V. Lisovskiy, V. Yegorenkov, J.-P. Booth, K. Landry, D. Douai, and V. Cassagne, J. Phys. D Appl. Phys. 43, 385203 (2010).

${ }^{43}$ M. Stano, N. Pinhão, D. Loffhagen, M. Kučera, Z. Donkó, and S. Matejčík, Eur. Phys. J. D 65, 489-498 (2011).

${ }^{44}$ R. Ono and T. Oda, Plasma Sources Sci. Technol. 18, 035006 (2009). 